\title{
Factors Predicting Late Collapse of Distal Radius Fractures
}

\author{
Neritan Myderrizi, MD \\ Regional Hospital Durres, Orthopaedic Clinic, Durres, Albania
}

\begin{abstract}
Background: Although fractures of the distal radius are a common clinical presentation, many factors affect instability of these injuries. The aim of this study was to assess the influence of age, sex, distal radial ulnar joint injury (DRUJ), ulnar styloid fracture, and dorsal displacement in late collapse of distal radius fractures. Methods: Three hundred twenty-nine patient fractures were measured for dorsal tilt, radial inclination and ulnar variance after reduction and 2 months later. Reduction loss was analysed statistically against variables like DRUJ involvement, ulnar styloid fractures, age, sex, and AO classification. Results: After two months there was loss of reduction in $171(51.9 \%)$ cases. Loss of reduction was related to age, AO classification, involvement of DRUJ, ulnar styloid fractures and initial displacement. Conclusions: Factors such as age, associated DRUJ injury, ulnar styloid fracture are predictive of loss of reduction. Knowing these predictor factors, can aid in decision regarding treatment methods.
\end{abstract}

Key Words:

Distal Radius Fracture, Radial Tilt, Ulnar Variance, Volar

Tilt, Ulnar Styloid Fracture, DRUJ

\section{INTRODUCTION}

There has been no consensus for treatment of distal radius fractures since 1814, when Abraham Colles described such fractures ${ }^{1}$. Conservative treatment with casting is not satisfactory in many cases. Trumble $a t a l^{2}$ reported loss of reduction a few weeks post initial treatment, despite excellent reduction in anatomic position. This is an important problem because malunion of distal radius fractures can lead to posttraumatic arthritis, mid carpal instability and pain ${ }^{3}$.

Conservative treatment of minimally displaced and stable fractures of the distal segment of the radius typically results in a good outcome but the treatment of severely displaced and unstable fractures has remained controversial. It is well known that there exists a strong correlation between anatomic reduction and the radiocarpal joint function ${ }^{4,5}$. There are a number of treatment methods ranging from internal to external fixation techniques that are used to restore and maintain the radiographic position until union of the fracture ${ }^{6}$.

Fractures of the distal radius continue to be commonly seen in Emergency Departments; further, conservative treatment continues to be the most commonly chosen modality. Typically, fractures that are not stable after reduction or at one week following immobilization are treated surgically. Several surgical techniques are available and their use depends on the type of fracture.

Importantly, a number of fractures that seem stable after reduction and immobilization show loss of reduction after 58 weeks. The aim of this study is to investigate if loss of reduction after conservative treatment is significantly associated with age, sex, ulnar styloid fractures, AO classification and/or distal radial ulnar joint (DRUJ) involvement.

\section{MATERIALS AND METHODS}

Patients who underwent conservative treatment for distal radius fractures in our department from 2006-2009 were included in this retrospective study. The exclusion criteria were fractures not primarily reduced under acceptable anatomic criteria, early unstable fractures that lost reduction within one week and paediatric fractures. Fractures were classified according to AO classification ${ }^{7}$.

Reduction was accomplished by manipulation (Charnley technique ${ }^{8}$ ) and initially immobilised with a cast splint and later with a below elbow full arm cast. All fractures were reduced according to acceptable anatomic criteria: radial tilt $>10^{\circ}$, ulnar variance $0 \mathrm{~mm}$, palmar tilt $>0^{\circ}$, no intraarticular displacement more than $2 \mathrm{~mm}$.

Length of immobilisation was 5-8 weeks. Radiography was performed before and after reduction and at 7, 20, and 42 days to evaluate healing. Fractures that lost reduction in one week were considered unstable and therefore excluded from the study. Late collapse was seen after 7 weeks of immobilization. Such late collapse was evaluated by radiographs taken at 2 months. Volar tilt, radial tilt and ulnar variance were measured on plain radiographs ${ }^{9}$. Other variables studied were age, sex, fracture type (AO), DRUJ involvement, and involvement of ulnar styloid fracture. 
Table I: Type of the fractures for every sex

\begin{tabular}{|lrrrrrrrrr|}
\hline Gender & & & & & & & & & \\
\\
Female & A2 & A3 & B1 & B2 & B3 & C1 & C2 & C3 & \\
Male & 124 & 27 & 9 & 6 & 1 & 12 & 22 & 8 & 208 \\
Total & 52 & 9 & 15 & 5 & 3 & 15 & 15 & 7 & 121 \\
$\%$ & 176 & 36 & 24 & 11 & 4 & 27 & 37 & 15 & 329 \\
& 53 & 11 & 7 & 3.3 & 1.2 & 4.3 & 11.2 & 4.6 & Total \\
\hline
\end{tabular}

Table II: Loss of reduction for every AO class in correlation with DRUJ injuries

\begin{tabular}{|llccccc|}
\hline AO Class & & No & $\begin{array}{c}\text { Loss of } \\
\text { reduction }\end{array}$ & $\begin{array}{c}\text { loss of } \\
\text { radial tilt }\end{array}$ & $\begin{array}{c}\text { Ulnae } \\
\text { variation }\end{array}$ & $\begin{array}{c}\text { Loss of dorsal } \\
\text { tilt }\end{array}$ \\
\hline A2 & DRUJ involvement & 52 & $37(71 \%)$ & $2(0-6)$ & $2(0-6)$ & $1(-6-6)$ \\
& No DRUJ involvement & 124 & $43(34 \%)$ & $1(0-8)$ & $1(0-6)$ & $1(-8-6)$ \\
A3 & DRUJ involvement & 27 & $27(100 \%)$ & $4(2-9)$ & $5(4-6)$ & $2(0-7)$ \\
& No DRUJ involvement & 9 & $7(78 \%)$ & $3(2-4)$ & $3(0-6)$ & $1(0-4)$ \\
B1 & DRUJ involvement & 0 & 0 & 0 & 0 & 0 \\
& No DRUJ involvement & 24 & $2(8 \%)$ & 0 & 0 & 0 \\
B2 & DRUJ involvement & 5 & $2(40 \%)$ & 0 & $1(0-4)$ & $-1(-6-9)$ \\
& No DRUJ involvement & 6 & $3(50 \%)$ & 0 & $1(0-4)$ & $4(-12-0)$ \\
B3 & DRUJ involvement & 1 & $1(100 \%)$ & 0 & 0 & 0 \\
& No DRUJ involvement & 2 & $2(100 \%)$ & 0 & 0 & $1(2-4)$ \\
C1 & DRUJ involvement & 7 & $5(71 \%)$ & $1(0-4)$ & $2(2-4)$ & $1(-6-6)$ \\
& No DRUJ involvement & 20 & $7(35 \%)$ & $1(0-4)$ & $1(0-4)$ & $0(-6-4)$ \\
C2 & DRUJ involvement & 32 & $26(81 \%)$ & $3(2-7)$ & $3(0-6)$ & $2(0-8)$ \\
& No DRUJ involvement & 5 & $5(100 \%)$ & $2(2-5)$ & $2(0-6)$ & $2(2-4)$ \\
C3 & DRUJ involvement & 12 & $10(83 \%)$ & $3(0-8)$ & $4(4-8)$ & $3(-4-8)$ \\
& No DRUJ involvement & 3 & $2(66 \%)$ & $2(2-5)$ & $1(2-4)$ & $0(0-2)$ \\
p value & (Mann-Whitney test) & & $<.0001$ & $<.0001$ & $<.0001$ & \\
& & & & & \\
\end{tabular}

Table III: Loss of reduction related to age, sex, initial displacement and fractures of ulnar styloid

\begin{tabular}{|c|c|c|c|c|c|}
\hline \multirow[t]{2}{*}{ Category } & \multirow[t]{2}{*}{ Patients } & \multirow[t]{2}{*}{ Loss of reduction } & \multicolumn{2}{|c|}{ Loss of angles-mean (range) } & \multirow[b]{2}{*}{ Dorsal tilt } \\
\hline & & & Radial tilt & $\begin{array}{l}\text { Ulnar variance } \\
(\mathrm{mm})\end{array}$ & \\
\hline$>70$ years & 53 & $40(83 \%)$ & $3(0-9)$ & $3(0-8)$ & $2(0-8)$ \\
\hline$<70$ years & 276 & $131(47 \%)$ & $2(0-8)$ & $1(0-8)$ & $1(0-12)$ \\
\hline$P$ value (Mann-Whitney test) & & & $<.0001$ & $<.0001$ & $<.0001$ \\
\hline Male & 121 & $50(41 \%)$ & $1(0-7)$ & $1(0-6)$ & $1(0-12)$ \\
\hline Female & 208 & $121(58 \%)$ & $2(0-9)$ & $2(0-8)$ & $2(0-8)$ \\
\hline$P$ value (Mann-Whitney test) & & & 0.0201 & 0.0015 & 0.0294 \\
\hline Fractures of ulna styloid & 138 & $97(70 \%)$ & $2(0-9)$ & $2(0-8)$ & $2(0-9)$ \\
\hline No fractures of ulnar styloid & 191 & $80(41 \%)$ & $1(0-8)$ & $1(0-8)$ & $1(0-12)$ \\
\hline$P$ value (Mann-Whitney test) & & & $<.0001$ & $<.0001$ & $<.0001$ \\
\hline Dorsal displacement & 153 & $121(79 \%)$ & $2(0-8)$ & $2(0-8)$ & $2(0-8)$ \\
\hline Minor displacement & 176 & $50(30 \%)$ & $1(0-8)$ & $1(0-9)$ & $1(0-12)$ \\
\hline$P$ value (Mann-Whitney test) & & & $<.0001$ & $<.0001$ & $<.0001$ \\
\hline All patients & 329 & & $2(0-9)$ & $2(0-8)$ & $2(0-12)$ \\
\hline
\end{tabular}




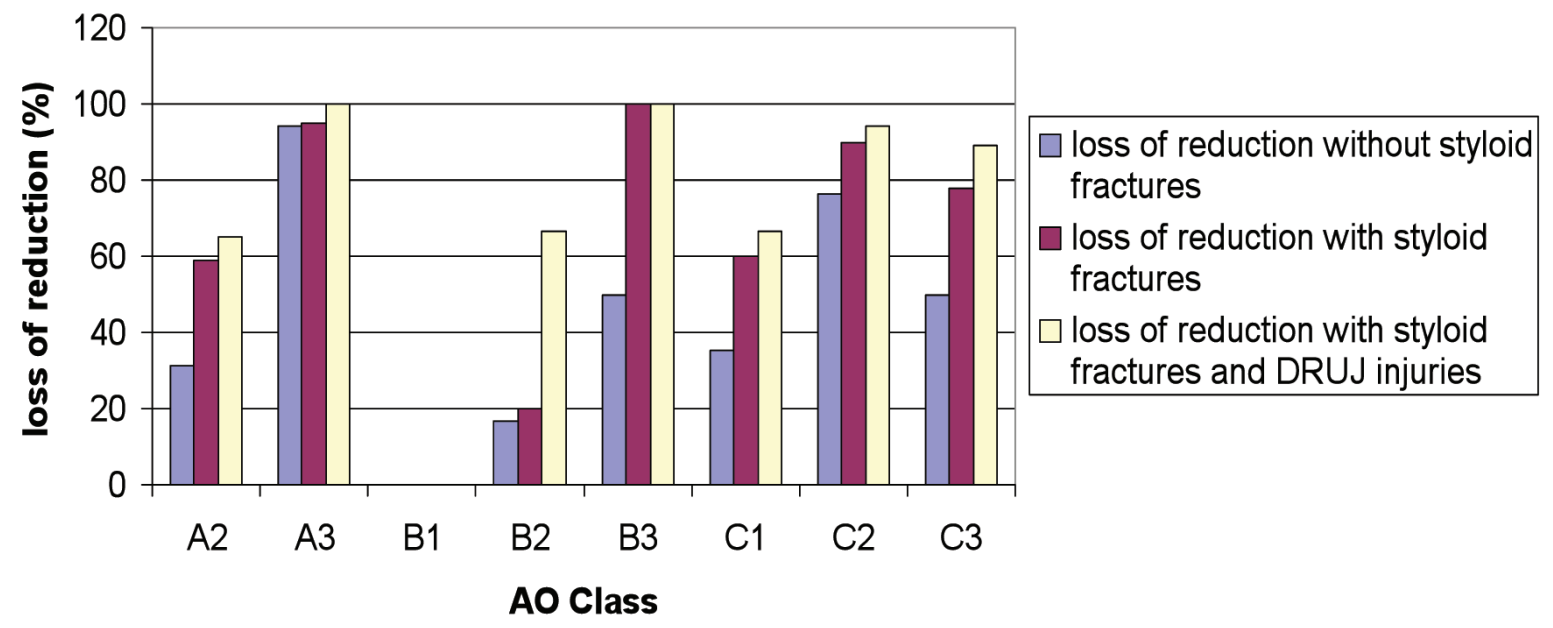

Fig. 1: Loss of reduction in cases with and without fractures of styloid process of ulnae and with concomitant fractures of ulnar styloid and DRUJ involvement. Correlation between loss of reduction and ulnar styloid fractures is stronger in case of concomitant DRUJ injuries.

Statistical analysis was performed using the Mann-Whitney test. P value of $<0.001$ was considered significant for the purposes of this study.

\section{RESULTS}

Three hundred twenty-nine cases of distal radius fracture were studied, of which 206 were female and 123 male with a mean age of 54.3 years old (range 18-82y). One hundred ninety-five were left hand fractures and 129 right hand, while 5 cases involved fractures of both hands. In 136 (41.3\%) patients there was associated DRUJ injury and 138 (42\%) had associated fractures of the ulnar styloid process. There was severe dorsal replacement in 153 fractures. All fractures were classified after AO-ASIF Classification. (Table 1)

All fractures were reduced so that the mean radial tilt was 20 degrees, ulnar variance was $0 \mathrm{~mm}$ and the mean palmar tilt was grade1. After two months there was loss of reduction in 171 cases (in type A3, B2, B3, C2, C3 injuries). This loss was more obvious in fractures which were associated with DRUJ injuries (Table 2)

There was also correlation between loss of anatomic reduction and age of the patients. In patients $>70$ years, this loss is more obvious. There was no correlation between sex and loss of reduction. However, there was correlation between ulnar styloid process fractures and loss of anatomic reduction. Fractures of the ulnar styloid alone were not significant but when analysed with concomitant DRUJ injury, this was found to be a prognostic indicator of late instability. (Figure 1)

\section{DISCUSSION}

With reference to fractures of the distal aspect of the radius, Dr. Abraham Colles stated, "One consolation only remains, that the limb will at some remote period again enjoy perfect freedom in all its motions, and be completely exempt from pain; the deformity, however, will remain undiminished throughout life ${ }^{1}$. Since 1814 , there has been continuing controversy about the best method of treatment for distal radius fractures. A central issue throughout has been the relationship between the final anatomical and the final functional result ${ }^{10}$.

The various surgical techniques for treating fractures of the distal radius are aimed at reducing final deformity to ensure better anatomical results especially in more severe fractures. Most distal radial fractures are uncomplicated and effectively treated with closed reduction and immobilization in a cast. The goal of treatment is to restore the functional anatomy by a method that does not compromise hand function. In most Emergency Departments of Regional Hospitals, the majority of fractures of distal radius are treated conservatively.

In the present study, there was loss of reduction in a considerable number of cases even though there was good anatomic reduction. This loss of reduction is related to a number of factors, which must be considered before deciding on a course of treatment. Important factors to consider include fracture type, age, and involvement of DRUJ injuries and/or ulnar styloid injuries.

Several studies about DRUJ injuries indicate association with distal radius fractures. Mackenney et $\mathrm{al}^{11}$ developed a formula to prognosticate late instability according to variables such as age, metaphyseal comminution and ulnar variance. We identified even more predictor factors of late instability in the present study. 
Patients with Colles' fractures, which extend into the DRUJ, have a worse prognosis.

There was also correlation between DRUJ injuries and loss of reduction, which was stronger in fracture types A3, C2, C3. Ligamentous structures around the DRUJ are strong stabilizers of the wrist joint, so any disruption of this mechanism may lead to instability. May et $a l^{16}$ have shown that $11 \%$ to $19 \%$ of patients with distal radius fractures suffered from problems of the DRUJ following these injuries. Other authors also report that distal radius fractures with DRUJ involvement have a worse prognosis than those fractures without DRUJ instability ${ }^{12}$.

Our results show a weak correlation between ulnar styloid fractures and loss of reduction. This correlation becomes stronger when fractures of ulnae styloid are associated with DRUJ injuries. (Figure 1). That means a more massive ligamentous injuries and the grade of instability will be greater. The significance of the association of ulnar styloid fractures, with a worse outcome is also disputed. Furthermore, several studies have found no correlation between ulnar styloid fractures and the end result ${ }^{13}$.

Patient age is another predictor of late instability, as there were increased number of patients with late fracture collapse who were over 70 years old. Osteoporosis leading to bone comminution is the main factor of this collapse. With aging, the solid cortical segments of bone become brittle, and the porous trabecular bone takes a significant role in load transmission ${ }^{14}$. However, sex does not seem to be related with loss of reduction.

Hove et $a l .{ }^{15}$ analysed data for 645 conservatively managed distal radial fractures. Using multiple regression analysis, the authors found that the initial dorsal angulation, radial length, and patient age were predictors of malunion. Lafontaine et $a l .{ }^{16}$ reported the following as predictors of fracture instability: age ( $>60$ years), dorsal angulation $\left(>20^{\circ}\right)$, dorsal comminution, intra-articular fracture (radiocarpal joint surface), and associated ulnar fracture. Again, all fractures in the study were initially displaced. Abbaszadegan et al. ${ }^{17}$ calculated the independent significance of a range of factors, and found that ulnar variance, Lidstrom class ${ }^{18}$, and patient age proved to be the most important. The authors also quantified the risk of instability but only with respect to ulnar variance.

Another predictor of late instability of anatomic reduction is initial dorsal displacement. We found a strong correlation between initial dorsal displacement and late instability. However, the dorsal angle alone without comminution is not an important predictive factor. Jenkins ${ }^{19}$ found that the position of the fracture at presentation was a good indicator of fracture position at union. He also found that the absence of dorsal comminution was protective against malunion in dorsal angulation. The grade of dorsal displacement and communition, except in fractures in which the distal fragment is dorsally translocated, is intimately related with further instability. This comminution of metaphysis explains also the late instability of the type $\mathrm{A} 3$ and $\mathrm{C} 2, \mathrm{C} 3$ fractures $^{20}$.

\section{CONCLUSION}

Factors such as age, DRUJ involvement, ulnar styloid fractures associated with DRUJ involvement and initial displacement are predictive of reduction loss. Even with an acceptable primary anatomic reduction, there may be reduction loss in certain fracture types (A3, B2, B3, C2, C3), after two months. Knowing that these factors are predictive, can aid in early decision-making as to the method of treatment. As these fractures are at high risk of late collapse, early surgical treatment should be the treatment of choice. Patients with low functional requirements are more likely to have only conservative treatment of these fractures. 


\section{REFERENCES}

1. Abraham Colles, The classic. On the fracture of the carpal extremity of the radius, Edinburgh Clin Orthop. 1972; 83: 3-5

2. Trumble YE, Schmitt SR, Vedder NB. Factors affecting functional outcome of displaced intraarticular distal radius fractures. $J$ Hand Surg 1994; 19: 325-40.

3. Adams BD. Effects of radial deformity on distal radioulnar joint mechanics. J Hand Surg [Am]. 1993; 18: 492-8.

4. Douglas P, Marci D, Thomas E: Wrist Fractures. Orthopaedic Clinics of North America. 33: 35-57.

5. Mackenney, M.M. McQueen, R. Elton: Prediction of Instability in Distal Radial Fractures. J. Bone Joint Surg. [Am]. 2006; 88: 1944-51.

6. Jupiter JB, Fernandez DL, Whipple TL, Richards RR. Intra-articular fractures of the distal radius: contemporary perspectives. Instr Course Lect. 1998; 47: 191-202.

7. Müller ME, Allgöwer M, Schneider R, and Willenegger H: Manual of Internal Fixation. Techniques Recommended by the AOASIF Group. Ed. 3. New York, Springer, 1991.

8. Oestern J: Distalen Radiusfrakturen. Grundlagen und Konservativen Therapie. Der Chirurg 1999; 70: 1180-92.

9. Hollevoet N, Verdonk R, The functional importance of malunion in distal radius fractures. Acta Orthop Belg 2003; 69(3): 23945.

10. King GJ, McMurtry RY, Rubenstein JD, Gertzbein SD. Kinematics of the distal radioulnar joint. J Hand Surg [Am]. 1986; 11: 798-804.

11. Mackenney MM, McQueen R Elton: Prediction of Instability in Distal Radial Fractures. J Bone Joint Surg. [Am]. 2006; 88: 194451.

12. May MM, Lawton JN, Blazar PE. Ulnar styloid fractures associated with distal radius fractures: incidence and implications for distal radioulnar joint instability. J Hand Surg [Am]. 2002; 27(6): 965-71.

13. Lindau T, Aspenberg P. The radioulnar joint in distal radial fractures. A review. Acta Orthop Scand 2002; 73 (5): 579-88.

14. Yan S, Michael A. K. Liebschner, Gemunu H. Gunaratne. A Study of Age-Related Architectural Changes that Are Most Damaging to Bones. Biophysical J 2004; 87: 3642-7.

15. Hove LM, Solheim E, Skjeie R, Sorensen FK. Prediction of secondary displacement in Colles' fracture. J Hand Surg [Br]. 1994; 19(6): 731-6.

16. Lafontaine M, Hardy D, Delince P. Stability assessment of distal radial fractures. Injury 1989; 20: 208-10.

17. Abbaszadegan H, Conradi P, Jonsson U. Fixation not needed for undisplaced Colles' fracture. Acta Orthop Scand. 1989; 60: 602.

18. Lidstrom A. Fractures of the distal end of the radius. A clinical and statistical study of end results. Acta Orthop Scand. 1959; 41: 1-118

19. Jenkins NH. The unstable Colles' fracture. J Hand Surg[Br]. 1989; 14: 149-54.

20. Newey ML, Ricketts D, and Roberts L: The AO classification of long bone fractures: an early study of its use in clinical practice. Injury, 1993; 24: 309-12. 